\title{
Incorporating Movie Clips to Validate Learning: A Students' Assessment
}

\begin{abstract}
By Esha Sekhri*
The use of movie-based educational interventions has been widely used in the pedagogy of psychology. Wherein most of the researchers have included fulllength movies in their teaching followed by students' comments of its effectiveness; the current research was carried out to examine if or not students will be able to find relevant clips from the list of movies provided and incorporate those in their group workshops after being exposed to the theoretical knowledge in their lecture class. To gauge how the participants received it and what suggestions do they have to offer for the improvement of this innovative exercise an anonymous survey and a semi open-ended interview was used. The research was conducted in three trimesters of academic years 2018 and 2019. On analysis of the raw data, it was found that the students rated the assignment favorably and reported that movie clips helped them understand the course material better and enabled them to apply psychological concepts to real-life situations. The findings suggest that movie clips can facilitate the learning process and can prove to be an efficacious tool to validate students' learning.
\end{abstract}

Keywords: education, movie-clips based learning, introduction to psychology, undergraduate elective course, validation of student learning

\section{Introduction}

"A unique property of film is its ability to make one see and grasp things which only the cinema is privileged to communicate" (Kracauer, 1973).

Cinema is well-known for its persuasiveness that can effortlessly hold its audiences' attention for longer periods (Hinde, Smith, \& Gilchrist, 2018). Research suggests that people in the USA spend 4 hours and 46 minutes watching film and TV every day (Fottrell, 2018), with worldwide cinema box office revenues at the US \$41.1 billion (Motion Picture Association of America - MPAA, 2019).

Beyond the classroom walls, students absorb massive volumes of information from feature films, a lot of which depicts psychological themes and undertones. They do this without really appreciating the underlying meaning of what is being viewed. By bringing movie-based learning to the classroom, educators can bridge the gap between ignorant out-of-school experiences and refined understanding of the deeper psychological issues portrayed in the movies. Thus, using movies in the classroom to understand pedagogy of psychology is an important research topic.

A comprehensive review of film studies literature suggests that the unique features of film make it an uncommonly powerful teaching tool (Champoux, 1999).

\footnotetext{
*Lecturer and Tutor, University of Wollongong in Dubai, UAE.
} 
Salomon (1979) found that individuals learn, new, novel and abstract concepts more easily when presented with both verbal and visual form. Movie learning scenarios present valuable opportunities for better identification and understanding of psychological issues. Movies encompass complex processes like symbolic representation (Sharma, Sharma, \& Ghai, 2013). The visual representation and interplay of emotions depicted in the movies provide firsthand perspective to its viewers. Thus, utilizing these in understanding intricate psychological concepts is expected to promote learning.

Film is not only most popular art form but also has tremendous pedagogical utility which ensures student engagement and motivation. Many theorists argue that films bring vivacity to courses (Wedding, Wongpakaran, \& Wongpakaran, 2017) and claim that films should be made an essential component of any curriculum. Owing to its usefulness and effectiveness, movies are being used by various researchers in their respective fields from the late 1970s. However, a surge of research publications was noticed in the late 1990s and since then, numerous articles containing critiques of films and creative ideas for incorporating films into classrooms have been published, for example, publications exist on educational use of movies in Counselor Education (Higgins \& Dermer, 2001; Holloway, Oxford, \& Wilzeck, 2016), History (Marcus, 2005), Law (Anderson, 1992), English as Second/Foreign Language (Bazilewich, 2009; Ekahitanond, 2011; Xhemaili, 2013), Medicine (Crellin \& Briones, 1995), Management education (Champoux, 1999), Sociology (Moskovich \& Sharf, 2012), Psychiatry (Sharma, Sharma, \& Ghai, 2013; Graf et al., 2014) and Psychology (Anderson, 1992; Badura, 2002; Bolt, 1976; Boyatzis, 1994; Dorris, 1978; Hauenstein \& Riddle, 2003; Lafferty, 2013; Paddock, Terranova, \& Giles, 2001; Petkari, 2017; RoskosEwoldsen \& Roskos-Ewoldsen, 2001; Searight \& Saunders, 2014; Smithikrai, 2016; Wedding, Wongpakaran, \& Wongpakaran, 2017).

\section{Literature Review}

\section{Discussions supporting Incorporating Movies in Pedagogy}

All the afore stated, and numerous other researches reiterate and reinforce the benefits of incorporating movies into pedagogy which include, but are not limited to, making course topics immediate, relevant, and concrete (Kinney, 1975; Moskovich \& Sharf, 2012; Nissim-Sabat, 1979); presenting behavior with such great intricacy and detailing that is not possible with other modes of instruction (Bolt, 1976). When coupled with deliberations and discussions, movies are found to encourage students' direct engagement with psychological concerns, which are integral in refining their critical thinking skills (Costin, 1982). Cowen (1984) stated that visual media make concepts more accessible to individuals than text media and help with later recall. Anderson (1992) indicated that movies improve analytical and perspective-taking skills. Roskos-Ewoldsen and Roskos-Ewoldsen (2001) argued that video clips heighten understanding and application of concepts, these also make concepts seem more realistic and class more enjoyable. 
Christopher, Walter, Marek, and Loenig (2004) suggested that movies offer greater understanding and application of concepts, make understanding easier than a textbook alone can do, and is a good supplement to lecturing. Furthermore, Morze (2008) suggested that movies enhance comprehension for refining critical thought and aid learners in examining new perspectives. Russell and Waters (2010) submitted that films bring people closer to people, events, and issues that they are studying. Films also enhance learners' learning experience and stimulate active participation (Ruusunen, 2011).

Sharma, Sharma, and Ghai (2013), in their paper, contended that using movies as a teaching tool create emotionally meaningful experiences that make far lasting impressions and are viewed as enjoyable and valuable by the students when compared to any other mode of presentation. Additionally, learning through aesthetics, which includes movies, stimulate learner reflection (Blasco et al., 2015).

Several researches have also hinted that movies support increased student involvement, motivation, engagement and learning (Holloway, Oxford, \& Wilczek, 2016; Kadivar et al., 2018). Another significant benefit of blending movies in the teaching-learning process, as professed by Smithikrai (2016), was that movies tap both affective and cognitive experiences of learners. The researcher further concluded that teaching with movies promote positive characteristics and behaviors. Wedding, Wongpakaran, and Wongpakaran (2017) in their research ingeminated that through the subtleties of editing and juxtaposition of sound and image, a good film can provide first-hand perspective, which is not easily imparted by lectures or textbooks. Last but not the least, movies have proven effectual in aiding recall of course content and exposure of students to authentic and realistic scenarios (Green, n.d.).

\section{Research Questions}

On a thorough reading of over 60 research papers and articles, following gaps were identified by the researcher - almost all the researches have exclusively focused on students majoring in psychology; the author of the current paper couldn't spot even a single study that was conducted on students taking psychology as an elective zero-level course. Furthermore, of all the explored researches none but one was carried out in the middle-eastern part of the world. Additionally, most of the researchers and educators have used full-length movies to critique either the psychological content of the movie or the exercise of movie viewing in general; effectiveness of using movie clips remains briefly addressed in the literature. Finally, almost every researcher has integrated movies in his/her teaching and has then studied its effect on students' enthusiasm, attitude or interest towards the exercise. In the current research, the students take the front seat and after being exposed to the contents of the chapter in the lecture they are expected to watch the movie from the listed movies and then find, edit and discuss the clips that are relevant to and cohesive with the contents taught in the class. In other words, movie clips were used as an instrument to validate students' learning and 
understanding of lecture contents. Based on above gaps, following research questions were formulated.

1. Will the students be able to critically analyze the movie and bring relevant clips from it to be discussed in their group workshops?

2. What do students think about the effectiveness of movie-clips based workshops as a tool to analyze psychological concepts?

3. What additional recommendations, comments or feedback do students have for improving the said assignment?

\section{Methodology}

\section{Sample}

The present research study was carried out in the Middle Eastern campus of a Western University, in a zero-level foundation course entitled Introduction to Psychology, in the fall trimester of 2018 and spring and summer trimesters of the year 2019.

A typical tutorial class for this course constitutes a heterogeneous population with mixed demographics, talents and learning backgrounds. All the tutorials are capped at 25 students per section. The total sample was distributed in 14 sections, of which the author of the study taught eight sections. All in all, the research sample comprised of 193 students of which 104 were male students and 89 females. The average age of the participants was 21.2 years. None of the students had previously received any specific instructions/training in using or critiquing Hollywood movie clips, although they had some exposure to educational videos, which were used by the course instructors in the same or other subjects.

In each tutorial, one group comprising 3-4 students were asked to present a 40-45 minutes group workshop on a chosen topic. Since, without proper guidance students might choose movies that may not offer optimal material for this assignment, hence, they were asked to pick one movie from the list provided by the course instructors (Please refer to Appendix I for the list of topics and movies provided). The students were further asked to present the contents and concepts of the chosen topic using the clips from that particular movie.

Each class section followed the same schedule. The presenters used movie clips as one of the teaching assistant forms along with other tools like PowerPoint presentations, explanation, discussions, activities and quizzes etc. The presenters announced the topic and movie to be discussed a week prior to their workshop and the remaining students (audiences) were encouraged to view the movie for a better understanding of the workshop. Presenters were asked to view, assess, edit and discuss the clips as a part of their learning experience. Presenters were also encouraged to review research papers written and published on the chosen movie. This exercise helped them understand and analyze the movie from a psychological perspective. Prior to discussion of movie clips, presenters provided a brief narrative of the broader topic along with a gist of the movie indicating the protagonist, main 
characters, plot and the storyline. Next, the presenters highlighted the underlying concepts that would be discussed using movie clips. The students were given free hand to use either inductive or deductive approach in explaining the concepts to their audiences. That is, they could either first show the movie clip and then explain the concept depicted or they could do the explanation first and then show relevant clips and ask the audiences to identify the phenomenon/idea depicted in the clip. The workshop was followed by an open class discussion involving the whole class. At the end of the workshop the students, both presenters and non-presenters, were encouraged to give their visceral critique of the movie clips and exercise.

After explaining the aim of the study to the participants and after obtaining verbal consent from them, students were asked to evaluate the assignment in terms of its effectiveness, novelty, being enjoyable, ease of understanding, application of concepts and its potency in stimulating class discussions.

Since, no single instrument can guarantee the complete truth (Hourigan, Leavy, \& Carroll, 2016) hence, a parallel convergent mixed-method approach was adopted i.e. the data was collected both quantitatively (using questionnaires) and qualitatively (using interviews) to determine the effectiveness of said assignment.

\section{Instruments}

\section{Questionnaire}

A student feedback questionnaire was administered at the end of the course to explore how students received this innovative movie clips based workshop, what did they think of its effectiveness and, whether or not this was helpful in understanding various psychological concepts. For this, an anonymous survey of students enrolled in author's tutorials $(\mathrm{N}=193)$ was done. The questionnaire asked six nominal and 21 ordinal questions to be answered on a four-point Likert scale. Four-point scale was chosen as by removing the midpoint option one is minimizing respondents' attempts to "please the interviewer or appear helpful or not be seen to give what they perceive to be a socially unacceptable answer" (Garland, 1991).

The core areas covered in the tool encapsulated items pertaining prior presentation, during presentation, post presentation and suggestions for improvement (Please refer to Appendix II for the questionnaire). Seven experts including two educationists, three psychologists and two language experts were asked to evaluate the content validity of the items on the questionnaire. Alongside 15 students, who had already taken the course in earlier semesters, also assessed the validity of the questionnaire. All the experts and students were asked to point out any items or words that they found ambiguous or had difficulty understanding. Their collective feedback was used to modify the items. The questionnaire's reliability was ascertained using Cronbach's alpha, which turned out to be fairly high (0.87), establishing the homogeneity of the test. The collected data was further analyzed using Statistical Package for the Social Sciences (SPSS) 24.0 software. 


\section{Interviews}

The qualitative data for the current research was obtained using the semistructured interviews. A total of 54 students participated voluntarily in the informal interview. The interview form consisted of three questions and was aimed to probe deeper into students' attitudes and feelings with regards to movie-clips based workshops. Additional suggestions for improving the assignment were also sought. Each interview lasted for about 15 minutes. All the interviews were audio recorded and were transcribed later.

\section{Students' Evaluation of the Assignment}

\section{Review of Survey Findings}

Quantitative method was used to analyze the responses obtained on the survey questionnaire. At this point, negative items were scored in the reverse order. To analyze the data obtained on the questionnaire SPSS 24.0 was utilized. This software provided information in the form of frequency distribution and percentages. The results obtained from the questionnaire show that in general most of the students (86.4-92\%) found movie-clips based workshops more enjoyable, useful and interesting. A fairly high percentage of partakers $(76.4 \%)$ affirmed that using movie clips was a novel way in delivering group workshops. A similarly high percentage of participants $(88.2 \%)$ stated that movie clips enhanced their understanding of concepts and enabled them to cognize difficult theoretical concepts in more realistic ways (82\%). Significantly large percentage $(70.2 \%)$ of participants strongly agreed/agreed that they felt more confident when talking about the movies. One reason for this could be that films have become a part and parcel of everyone's life and when one talks about movies, he/she feels more assured about it. A lion's share (73.2\%) believed that movies are a good means to get young people enthusiastic about their subject and/or topic. Major chunk of the undergraduates $(65.8 \%)$ averred that they enjoyed other groups' workshop. There was a little decline in the results in this question as compared to all other items on the questionnaire because not all audiences watched the movies prior to the group workshop, which marred their interest in other groups' workshop. 68\% participants strongly agreed/agreed that having movie-clips based workshop helped in stimulating class discussions and almost similar percentage $(71.5 \%)$ established that they were asked invigorating questions about their workshops. When asked whether they would recommend the use of movie clips in future use and in other courses, a high proportion $-78.2 \%$ and $75.6 \%$ respectively - provided affirmative responses.

Furthermore, a lion's share of the participants (93.2\%) established that using movie clips was a wonderful tool for teaching and learning of psychology and its concepts. On an equal footing, $87.8 \%$ of the students believed that movie-clips based workshops are better than lecture style workshops. When enquired about learning the course contents using movie-based workshops, $85.4 \%$ of the 
participants indicated that this mode of delivery minimized rote-memorization substantially. Several students $(77.4 \%)$ avowed that they became more interested in their psychology class because it included an assessment containing movies.

On the negative items in the questionnaire, a steep decline was noticed in the affirmative responses. A marginal part (19.7\%) of the research partakers found fetching relevant clips from the movie arduous. Likewise, miniscule portion (16.4\%) of the participants believed that weighting for the said assignment was too much. A similar proportion of members $(18.3 \%)$ believed that working on group workshops using movie clips was more time consuming than other assignments. Finally, almost one-third (33\%) of the students believed that full-length movies should be used in the classroom over short clips. Although it seems like a fairly high percentage, but it is worth noting that these responses came from those participants who didn't watch the movie beforehand and hence wanted lecture timings to be devoted to viewing the movie.

The last item was intended to capture the overall emotion of the activity and it was found that major chunk of the participants $(89.1 \%)$ established that the said assignment was the highlight of their Introduction to Psychology course.

Conclusively, the survey data clearly indicated that students enjoyed all aspects of this novel assignment. Although all other assignments provide a brief glimpse into psychology, they fall short of creating the actual climate that enhances students' comprehension of the subject (Higgins \& Dermer, 2001). Movies provide an opportunity to observe body language, facial expressions, interactions between the characters and even the social environment in which the interactions take place. Consequently, they fill the void that remains in using one-dimensional sources of information like written examinations, essays, reflective pieces, posters, presentations etc.

\section{Review of Findings for the Interview}

The most emergent theme while analyzing interviews was that movie clips based group workshop was an interesting, innovative and inspirational exercise as can be seen from the following testimonies,

"It was really interesting, the things that I learnt in the lecture, I am seeing them live in the film. I could constantly reflect on what I was seeing."

Another comment included,

"when you hear the word movie, first thing that pops in your head is fun or a reward or leisure time activity ... little did I know that these can be exceptionally valuable in understanding academic content as well ... a very innovative approach, I must admit!"

Many participants, through their testaments, averred that the current project contributed largely to deep learning and understanding of psychological concepts; a comment that highlights this emotion includes, 
"I am not someone who can rote memorize stuff, I need to understand and apply what I have received in lectures ... movies have done just that ... they contributed to my deeper learning as opposed to the superficial learning, which normally doesn't happen in a zero-level course".

The connection that got established between theoretical knowledge received in lectures and real life examples displayed in movies was highly appreciated by all the participants, for example, a member of the group who presented on the topic of 'psychological disorders' stated,

"Film offered a unique opportunity to seek realistic manifestations of a person suffering from schizophrenia. I also got to know how films can, (sometimes) offer an inaccurate portrayal of a mental disorder..."

Another student commented on clarity and true-to-life experiences rendered by movies and how these helped in making psychological ideas more tangible

"movie clips based workshops helped me academically, it simplified the content, made it more concrete and made concepts and long theories more realistic."

Yet another participant, who was interning in a Multinational Company, drew parallels between case studies and movies,

"I have worked on several projects involving case studies ... films, are a visual representation of those case studies and hence, are more appealing, evocative and enthralling. I'll ask my reporting manager to inculcate movie clips in our training sessions as well."

The role of movies in providing firsthand view was also highlighted in a few testimonies,

"I liked learning through movies... movie doesn't teach you like a book... you can actually see it happening, you get a glimpse of what it is to live with amnesia (for instance) ... it provides you with first hand perspective of people's lives and their stories."

Another student expressed a similar sentiment,

"as an engineer, I don't have any examples or experiences to draw while understanding a few psychological concepts like disorders or therapies or even certain theories ... movies filled that void ... films made me a critical analyzer of psychological concepts."

Another student commented on the familiarity and attention-binding capacity of the movies,

"Films are well-known, attention-capturing medium ... no one needs to be coaxed into watching movies, you know ... so when I heard that we will be using movies in 
the course, it increased my motivation for attending the class ... and as expected, my 13-weeks experience has been so rewarding."

An undergraduate mentioned how (before watching the film),

"some of the notions and theories had been vague, it seemed like a lot of content to be memorized for a zero-level course, but after viewing the movie, everything fell into place ... it seemed like all the dots, that I thought could never be connected, got connected."

Another star student (whose group got the highest marks in the said assignment in Spring semester of 2019) highlighted the importance of discussions that followed the group workshop,

"the best thing about this workshop was the discussions that followed it ... it not just stimulated me or other high achievers, but even got the less participating ones talking. The clarity achieved by discussions added more to my knowledge repertoire. I would love to see and be a part of such workshops in my other subjects as well."

One student highlighted the emotions evoked by movies over a regular activity-based workshop,

"films strike a chord, these evoke emotions and make you feel a connection with the character being portrayed, as if he was portraying the journey of your life ... and when such a connection is made, study becomes a story ... a story you can relate to ... a story that you don't need to memorize."

Another student built her argument on the learning style, she claimed,

"I am a visual learner, I learn better when I see things over just reading from the book ... including movies in our course was such a brilliant idea ... I am sure many students would have benefitted from this exercise."

The same student further proposed the idea of having a library of movies and movie clips,

"we must build a library of movie clips relating to the course contents so that all visual learners, like myself, can benefit from it."

The flexibility of anytime anywhere viewing was also highlighted by one of the participants,

"when you (the instructor) first announced that group workshops are going to be movie clips based, I thought we will have to watch the movie in the lectures and then bring the relevant clips to the tutorial classes ... but the flexibility conferred by this style of workshop was amazing ... I could pause, play, pause as and when required..."

Similar opinion was seconded by another member of the same group, 
"At first I thought, we will be able to find only 5-6 relevant clips but when we watched the movie, it seemed like every other scene is related to the contents taught in the class. We revisited the full-length movie three times and we dipped in and out several times before we were able to carefully scrutinize at least 17 clips that could put our message across."

One student mentioned that the idea of having a movie clips based workshop seemed childish at first,

"at first it seemed impractical ... nobody likes change, there is always some resistance because of unfamiliarity ... I mean, it's a completely different way of thinking ... how can someone teach using movie clips, you cannot expect everyone would have seen the movie beforehand and expecting the presenters to give an overall view in five minutes also seemed lame ... but everyone got so fascinated by the idea of movie that almost everyone seemed to have enjoyed this activity thoroughly."

When asked about additional recommendations, comments or feedback for improving the assignment, most of the students avowed that the exercise needs no alteration and that it is highly effective in terms of the objectives it aims to accomplish. However, a handful of students provided suggestions for making the assignment more effectual and successful. Samples include:

"It would be better if you use the similar strategy in our lecture classes as well ... movies evoke discussion ... it can be a pleasant break from the lecture format."

"I know it can be a time constraint but it would be better if we could be made to see full-length movies in lecture class or a separate two-hour class. This way each and every one would have participated and benefited from the discussions that happen in the tutorials."

"I feel we must also be asked to submit a report containing an overall critique of the movie, owing to time constraints, the presenters (sometimes) are not able to show all the clips that they have identified ... like we identified more than twenty clips in 'The curious case of Benjamin Button' but were able to show only 12 of them ... had we been given more time or additional assignment like a report or essay, we would have showcased our hard work in its totality."

A similar sentiment was expressed by another student,

"I feel we should give at least $35 \%$ weighting to this assignment - 20\% for the group workshop and remaining $15 \%$ to the group report that the presenters should be asked to submit - we'll benefit more from this exercise if it accompanies a report submission as well."

Another important suggestion highlighted was the provision of list of recommended readings, 
"The obligation to read scholarly research articles and incorporating the findings in the workshop is really good, though it would have been better if you (the instructor) provided the recommended reading list ... that would have made the work lighter and concentrated."

\section{Discussion}

The objective of this study was to validate students' learning of psychological concepts using Hollywood movie-clips based workshops. To this aim three research questions were formulated. The following discussion considers each in turn. First of all, nearly all the groups did a marvelous job at analyzing the movie and bringing subsequent clips from it to be discussed in the class. This research question was majorly answered using researcher's observation and assessment of students' workshops along with the feedback interviews of the participants. All but one of the groups brought more than 8 clips that were highly relevant to and cohesive with the contents taught in the lecture. Many groups thought that the time limit imposed on them was the major drawback of this assignment as they had identified more clips to illustrate the concepts than they could actually show in the class. Students also highlighted the importance of proper guidance that was provided to them in the beginning of the semester. They averred that some handholding was required for this exercise, as they had never done such an assignment before. Clarity of instructions is critical for students' performance when trying a new assessment. Sowell (2017) has precisely captured this sentiment when he claimed that instruction giving has a direct effect on learning; a lesson or activity becomes chaotic and fails when students do not understand what they are supposed to do.

The second question was explored using both an anonymous survey as well as a semi-open ended interview. The participants were asked to share their thoughts about the effectiveness of innovative movie-clips based group workshops in comprehending and analyzing psychological concepts. The results obtained from quantitative data indicated that participants thoroughly enjoyed this useful, interesting, avant-garde and spellbinding activity. These findings are in line with Wiertelak (2002) and Wedding, Wongpakaran, and Wongpakaran (2017). Furthermore, the findings of this study reveal that using movies to understand psychology has solid advantages including enhanced understanding of psychological concepts, presenting abstract ideas concretely and in a more realistic way, and facilitating class discussions. This is in agreement with a number of studies (for example, Boyatzis, 1994; Christopher, Walter, Marek, \& Loenig, 2004; Conner, 1996; Davidson, 1990; Kinney, 1975; Moskovich \& Sharf, 2012; Nissim-Sabat, 1979). Reflections after the workshop promoted discussions, which in turn furthered learners' critical thinking skills, this finding supports the conclusions established by Costin (1982). A highly affirmative response on recommendation of the activity for future use in same as well as other courses insinuate that partakers found it to be a highly rewarding and stimulating experience. This is consistent with what has been found in the previous studies including Bluestone (2000) and Ruusunen (2011). 
The qualitative results established by the informal interview harmonized with the results obtained on the quantitative spectrum of the current research study. Many students voiced their opinions, thoughts and feelings on the effectiveness, usefulness as well on the ways of improving the said assignment. The most common reactions among the students after their workshop were that it was a fun, motivating and attention-grabbing assignment. A similar pattern of results was obtained in Gee and Dyck (1998), Kirsh (1998), Sharma, Sharma, and Ghai (2013) and Shin (2017). The connection that got established between the four walls of the lecture theatre and the world outside it was deeply appreciated by all the participants. A similar conclusion was reached by Hyler and Moore (1996) and Davis (2000) who asserted that movies aid the application of concepts from the coursework to real life.

The pedagogical gains in having movie-clips based workshops was seen both on individual and group levels. On individual level, it fostered reflection, created emotionally meaningful experiences, evoked emotions and promoted deep learning over superficial rote learning; on group level a collective team effort was observed. Other researchers like Sharma, Sharma, and Ghai (2013), Blasco et al. (2015) and Tan (2018) support such observations. Realization of reflective skills and other higher order skills require hands-on experience and in-depth discussions, both of which were vital components of this exercise. One of the most repeated sentiments was that such a task is highly beneficial in understanding academic content. This finding is consistent with what has been found in previous studies like Salomon (1979) and Cowen (1984).

Last but not the least, when enquired about the suggestions and recommendations to improve the assignment, some students averred that the activity could be made more relevant if similar strategy be used in lecture classes as well. Their line of thinking was that more exposure would lead to better outcomes and viewing a role-model incorporating similar strategy in her teaching would proffer more clarity to use clips judiciously. A further novel finding of this research was students' opinion on submission of report alongside the group workshop. Participants believed that owing to time barriers they were not able to showcase their efforts in entirety and hence, if they were asked to submit a written report, the assignment would have been better justified. In line with this proposal, the students demanded the weighting of the assignment to be increased from $20 \%$ to at least $35 \%$. They felt that finding scholarly articles for an assignment worth $20 \%$ for a zero-level course was a lot of work to do and that the provision of list of recommended readings from the instructors would have made their work lighter, easier and more fun.

All in all, the present study provided fresh evidence that using films in psychology courses, and specifically in introductory psychology course, can promote active learning; minimize rote learning and; encourage high level of involvement. 


\section{Limitations and Recommendations for Future Research}

Every study, no matter how well it is conducted and constructed, has certain limitations (Simon \& Goes, 2013). The primary limitation to the generalization of the results obtained in the current paper is its sample size. The study was conducted in one of the western universities in United Arab Emirates with the students who opted Introduction to Psychology as their elective course. Future researchers can further the findings of this research by conducting it on students enrolled in another universities across the country. A comparative study within various elective courses viz. sociology and philosophy can also be done.

Additionally, the time frame in which the researcher conducted the study was very limited. The investigator could not investigate how much this intervention can aid the retention of content and topics in long run. To see the said effects, further research can be done on the same sample after an interval of six months to one year. Another limitation of this research is its design, which used only survey and interviews to gauge the effectiveness of the intervention. A fully experimental pretest post-test design would be more powerful to test the efficacy and success of the assignment. Another area worth investigating is the comparison of grades obtained in the movie-clips based workshops with the performance on other oral and written assignments. This will provide a better insight of the usefulness of movies to teach and learn psychological concepts. Last and the final proposal for future inquiry came directly from students' interview where they recommended the submission of reflective and/or informative report to showcase their efforts in totality.

\section{Conclusion}

Through an analysis of questionnaire and interview responses, the current study, has provided converging evidence that the use of movie clips adds value to the process of learning of psychological concepts and creates motivation in the learning environment. Based on the results of the study, it can be safely concluded that using movie clips in group workshops stimulates class discussions, generates student interest and has a noteworthy effect on their understanding and retention of psychological concepts. Students' evaluations of the assignment provided a clear indication that this assignment was well received by them and they want it to be replicated in the pedagogy of other modules and courses as well. Conclusively, through the current research paper the researcher strongly advocates the use of movie clips to validate students' learning.

\section{References}

Anderson, D. D. (1992). Using Feature Films as Tools for Analysis in a Psychology and Law Course. Teaching of Psychology, 19(3), 155-158.

Arnold, B. (Producer), Lima, K., \& Buck, C. (Directors) (1999). Tarzan [Motion Picture]. United States: Walt Disney Pictures/Walt Disney Feature Animation. 
Badura, A. S. (2002). Capturing Students' Attention: Movie Clips Set the Stage for Learning in Abnormal Psychology. Teaching of Psychology, 29(1), 58-60.

Bazilewich, A. (2009). Beyond Adaptation: Using Film to Enhance the Teaching of Literature in the Secondary English Language Arts Classroom. Unpublished Master's Graduating Paper. Vancouver, Canada: The University of British Columbia.

Bender, L. (Producer) \& Van Sant, G. (Director) (1997). Goodwill Hunting [Motion Picture]. United States: Be Gentlemen.

Besson-Silla, V. (Producer) \& Besson, L. (Director) (2014). Lucy [Motion Picture]. France: EuropaCorp/TF1 Films Production/Canal+/Cine+/TF1.

Blasco, P. G., Moreto, G., Blasco, M. G., Levites, M. R., \& Janaudis, M. A. (2015). Education through Movies: Improving Teaching Skills and Fostering Reflection among Students and Teachers. Journal for Learning through the Arts: A Research Journal on Arts Integration in Schools and Communities, 11(1).

Blomkamp, N., Kinberg, S. (Producers) \& Blomkamp, N. (Director) (2015). Chappie [Motion Picture].United States: Columbia Pictures/MRC/LStarCapital/Kinberg Genre.

Bluestone, C. (2000). Feature Films as a Teaching Tool. College Teaching, 48(4), 141-146.

Bolt, M. (1976). Using Films Based on Literature in Teaching Psychology. Teaching of Psychology, 3(4), 189-190.

Boyatzis, C. J. (1994). Using Feature Films to Teach Social Development. Teaching of Psychology, 21(2), 99-101.

Boyle, D., Colson, C., Smithson, J. (Producers) \& Boyle, D. (Director) (2010). 127 hours [Motion Picture]. United Kingdom/United States: Pathé/Everest Entertainment/Film4 Productions/HandMade Films/Cloud Eight Films.

Chaffin, C., Kennedy, K., Marshall, F. (Producers) \& Fincher, D. (Director) (2008). The Curious Case of Benjamin Button [Motion Picture]. United States: Paramount pictures/Warner Bros. Pictures.

Champoux, J. E. (1999). Film as a Teaching Resource. Journal of Management Inquiry, 8(2), 206-217.

Christopher, A. N., Walter, J. L., Marek, P., \& Koenig, C. S. (2004). Using a "New Classic Film to Teach about Stereotyping and Prejudice. Teaching of Psychology, 31, 199202.

Conner, D. B. (1996). From Monty Python to Total Recall: A Feature Film Activity for the Cognitive Psychology Course. Teaching of Psychology, 23(1), 33-35.

Costin, F. (1982). Some Thoughts on General Education and the Teaching of Undergraduate Psychology. Teaching of Psychology, 9(1), 26-28.

Cowen, P. S. (1984). Film and Text: Order Effects in Recall and Social Inferences. Educational Communication and Technology: A Journal of Theory, Research, and Development, 32(3), 131-144.

Crellin, J. K., \& Briones, A. F. (1995). Movies in Medical Education. Journal of the Association of American Medical Colleges, 70(9), 745.

Davidson, W. B. (1990). The Dirty Dozen: Classroom Demonstration of Twelve Instigators of Aggression. Teaching of Psychology, 17(4), 252-253.

Davis, A. (2000). Using Feature Film in Rehabilitation Counselor Education. Rehab Education, 14(2), 169-180.

Dixon, L., Kroopf, S., Kavanaugh, R. (Producers) \& Burger, N. (Director) (2011). Limitless [Motion Picture]. United States: Virgin Produced/Rogue.

Dorris, W. (1978). Social Psychology and Sex Roles in Films. Teaching of Psychology, 5(3), 168-169.

Ekahitanond, V. (2011). Learn, Think, Act: Using Movies to Develop Critical Thinking Skills. Executive Journal, 31(3), 110-114. 
Emery, B., Friedmann, L., Lauder, K., Little, G., McQuarrie, C. (Producers) \& Alvarez, K. P. (Director) (2015). The Stanford Prison Experiment [Motion Picture]. United States: Abandon Pictures/Coup d'Etat Films/Sandbar Pictures.

Evans, B. A., Gideon, R., Scheinman, A. (Producers) \& Reiner, R. (Director) (1986). Stand by me [Motion Picture]. United States: Act III Productions.

Fonda, H., Rose, R. (Producers) \& Lumet, S. (Director) (1957). 12 Angry Men [Motion Picture]. United States: Orion-Nova Productions.

Fottrell, Q. (2018, August 4). People spend most of their waking hours staring at screens. Retrieved from: https://www.marketwatch.com/story/people-are-spending-most-oftheir-waking-hours-staring-at-screens-2018-08-01. [Accessed 12 February 2021]

Garland, R. (1991). The Mid-Point on a Rating Scale: Is it Desirable? Marketing Bulletin, 1991(2), 66-70.

Gee, N. R., \& Dyck, J. L. (1998). Using a Videotape Clip to Demonstrate the Fallibility of Eyewitness Testimony. Teaching of Psychology, 25(2), 138-140.

Graf, H., Abler, B., Weydt, P., Kammer, T., \& Plener, P. L. (2014). Development, Implementation, and Evaluation of a Movie-Based Curriculum to Teach Psychopathology. Teaching and Learning in Medicine, 26(1), 86-89.

Grazer, B., Howard, R. (Producers) \& Howard, R. (Director) (2001). A Beautiful Mind. [Motion Picture]. United States: Universal Pictures/DreamWorks Pictures.

Green, R. J. (n.d). Teaching Psychology through Film. Video. Association for Psychological Science.

Hauenstein, N. \& Riddle, D. (2003). Education and Training in I-O Psychology. The Industrial Organizational Psychologist, 41(1), 83-95.

Higgins, J. A., \& Dermer, S. (2001). The Use of Film in Marriage and Family Counselor Education. Counselor Education and Supervision, 40(3), 182-192.

Hinde, S., Smith, T., \& Gilchrist, I. (2018). Does Narrative Drive Dynamic Attention to a Prolonged Stimulus? Cognitive Research: Principles and Implications, 3(45).

Holloway, L. J. M., Oxford, R. L., \& Wilczek, R. S. (2016). Using Films to Teach Counseling Psychology in a Media-Drenched Culture. International Journal of Education and Social Sciences, 3(11), 31-38.

Hourigan, M., Leavy, A. M., \& Carroll, C. (2016). 'Come in with an Open Mind': Changing Attitudes towards Mathematics in Primary Teacher Education. Educational Research, 58(3), 319-346.

Hyler, S. E., \& Moore, J. (1996). Teaching Psychiatry? Let Hollywood Help! Academic Psychiatry, 20(4), 212-219.

Kadivar, M., Mafinejad, M. K., Bazzaz, J. T., Mirzazadeh, A., \& Jannat, Z. (2018). Cinemedicine: Using Movies to Improve Students Understanding of Psychosocial Aspects of Medicine. Annals of Medicine and Surgery, 28(Feb), 23-27.

Kinney, D. K. (1975). Cinema Thrillers: Reviews of Films Highly Rated by Psychology Students. Teaching of Psychology, 2(4), 183-186.

Kirsh, S. J. (1998). Using Animated Films to Teach Social and Personality Development. Teaching of Psychology, 25(1), 49-51.

Kracauer, S. (1973). Theory of Film: The Redemption of Physical Reality. New York: Oxford University Press.

Lafferty, M. E. (2013). Using Feature Films in the Teaching and Assessment of Sport Psychology. Sports and Exercise Psychology Review, 9(2), 74-82.

Lerner, A., Marshall, L., Gill, M., O’Toole, M., Scott, R. (Producers) \& Joffé, R. (Director) (2014). Before I Go to Sleep [Motion Picture]. United Kingdom/United States/France/ Sweden: StudioCanal/Millennium Films/Scott Free Productions/Film i Vãst. 
Liman, D., Crowley, P., Gladstein, R. N. (Producers) \& Liman, D. (Director) (2002). The Bourne Identity [Motion Picture]. United States/Germany: Hypnotic/Kennedy/ Marshall.

Linklater, R., Sutherland, C., Sehring, J., Sloss, J. (Producers) \& Linklater, R. (Director) (2014). Boyhood [Motion Picture]. United States: IFC Productions/Detour Filmproduction/Cinetic Media.

Linson, A., Chaffin, C., Bell, R. G. (Producers) \& Fincher, D. (Director) (1999). Fight Club [Motion Picture]. United States: Fox 2000 Pictures/Regency Enterprises/Linson Films.

Marcus, A. S. (2005). "It is as it was": Feature Film in History Classroom. Social Studies, 96(2), 61-67.

Morze, L. (2008). Beyond the Clip: Critical Uses of Film in the Non-Film Course. Human Architecture: Journal of Sociology of Self-Knowledge, 6(1), 1-6.

Moskovich, Y., \& Sharf, S. (2012). Using Films as a Tool for Active Learning in Teaching Sociology. The Journal of Effective Teaching, 12(1), 53-63.

Motion Picture Association of America - MPAA (2019). 2018 Theatrical Home Entertainment Market Environment (THEME) Report. Retrieved from https://www. motionpictures.org/research-docs/2018-theatrical-home-entertainment-market-envi ronment-theme-report. [Accessed 12 February 2021]

Nissim-Sabat, D. (1979). The Teaching of Abnormal Psychology through the Cinema. Teaching of Psychology, 6(2), 121-123.

Paddock, J. R., Terranova, S., \& Giles, L. (2001). SASB Goes Hollywood: Teaching Personality Theories through Movies. Teaching of Psychology, 28(2), 117-121.

Petkari, E. (2017). Building Beautiful Minds: Teaching through Movies to Tackle Stigma in Psychology Students in the UAE. Academic Psychiatry, 41(6), 724-732.

Roskos-Ewoldsen, D. R., \& Roskos-Ewoldsen, B. (2001). Using Video Clips to Teach Social Psychology. Teaching of Psychology, 28(3), 212-215.

Rudin, S., Brunetti, D., De Luca, M., Chaffin, C. (Producers) \& Fincher, D. (Director) (2010). The Social Network [Motion Picture]. United States: Columbia Pictures/ Relativity Media/Scott Rudin Productions/Michael De Luca Productions/Trigger Street Productions.

Russell, W. B., \& Waters, S. (2010). Reel Character Education: A Cinematic Approach to Character Development. Charlotte, NC: Information Age Publishing.

Ruusunen, V. (2011). Using Movies in EFL Teaching: The Point of View of Teachers. Unpublished Master's Thesis. Jyväsklä, Finland: University of Jyväsklä, Finland.

Salomon, G. (1979). Interaction of Media, Cognition and Learning: An Exploration of how Symbolic Forms Cultivate Mental Skills and Affect Knowledge Acquisition. San Francisco: Jossey-Bass.

Schwary, R. L. (Producer) \& Redford, R. (Director. (1980). Ordinary People [Motion Picture]. United States: Wildwood Enterprises, Inc.

Searight, H. R., \& Saunders, D. (2014). Teaching Psychology through Popular Film: A curriculum. International Journal of Social Science and Education, 4(4), 858-862.

Selznick, D. O. (Producer) \& Hitchcock, A. (Director) (1945). Spellbound [Motion Picture]. United States: Selznick International Pictures/Vanguard Films.

Sharma, N., Sharma, S., \& Ghai, S. (2013). Psychiatry Movie Club: An Innovative Way to Teach Psychiatry. Delhi Psychiatry Journal, 16(2), 335-342.

Shin, M. H. (2017). The Effects of Movie-Based Learning Project on Students' English Learning Motivation. Journal of Engineering and Applied Sciences, 12(14), 35613564 . 
Shyamalan, M. N., Blum, J., Bienstock, M. (Producers) \& Shyamalan, M. N. (Director) (2016). Split [Motion Picture]. United States: Blinding Edge Pictures/Blumhouse Productions

Simon, M. K., \& Goes, J. (2013). Dissertation and Scholarly Research: Recipes for Success. Seattle, WA: Dissertation Success LLC.

Smith, W., Black, T., Blumenthal, J., Lassiter. J., Steve, T. (Producers) \& Muccino, G. (Director) (2006). The Pursuit of Happiness [Motion Picture].United States: Relativity Media/Overbrook Entertainment/Escape Artists.

Smithikrai, C. (2016). Effectiveness of Teaching with Movies to Promote Positive Characteristics and Behaviors. Procedia - Social and Behavioral Sciences, 217 (2016), 522-530.

Sowell, J. (2017). Good Instruction-Giving in the Second-Language Classroom. English Teaching Forum, 55(3), 10-19.

Tan, E. S. (2018). A Psychology of Film. Palgrave Communications, 4(82).

Tanen, N., Hughes, J. (Producers) \& Hughes, J. (Director) (1985). The Breakfast Club [Motion Picture]. United States: A\&M films/Channel Productions.

Todd, S., Todd, J. (Producers) \& Nolan, C. (Director) (2000). Memento [Motion Picture]. United States: Summit Entertainment/Team Todd.

Wedding, D., Wongpakaran, N., \& Wongpakaran, T. (2017). The Use of Films to Enhance Pedagogy in the Psychology Classroom. In G. J. Rich, U. Gielen, H. Takooshian (eds.), Internationalizing the Teaching of Psychology. Information Age Publishing.

Wiertelak, E. P. (2002). And the Winner is: Inviting Hollywood into the Neuroscience Classroom. Journal of Undergraduate Neuroscience Education, 1(1), A4-A17.

Xhemaili, M. (2013). The Advantages of Using Films to Enhance Students' Reading Skills in EFL Classroom. Academic Journal of Interdisciplinary Studies, 4(13), 6266. 


\section{Appendix 1.}

\section{Workshop Topics and Suggested Movies}

\begin{tabular}{|l|c|}
\hline Group Workshop Topics & Suggested Movies \\
\hline $\begin{array}{l}\text { Consciousness } \\
\text { (Altered state: Usage of drugs) }\end{array}$ & $\begin{array}{c}\text { Limitless (Dixon, Kroopf, Kavanaugh, \& } \\
\text { Burger, 2011); Lucy (Besson-Silla \& } \\
\text { Besson, 2014) }\end{array}$ \\
\hline \multirow{3}{*}{ Learning } & Tarzan (Arnold, Lima, \& Buck, 1999); \\
& Chappie (Blomkamp, Blomkamp, \& \\
Kinberg, 2015)
\end{tabular}




\section{Appendix 2}

\section{Questionnaire for Students}

The purpose of the survey is to gather information concerning your opinion regarding the effectiveness of movie clips based workshops. Choose the bestsuited option among Strongly Agree, Agree, Disagree and Strongly Disagree. There are no right or wrong answers. It should take about 10 minutes to complete the survey. All responses are kept confidential. Please return the survey sheet to the instructor once you are finished answering.

Full Name of the Participant:

Sex:

Age (in years):

Major Area of Study:

University level:

Male _Female

Prior experience with teaching with movie clips:

\begin{tabular}{|c|c|c|c|c|c|c|}
\hline $\begin{array}{l}\text { S. } \\
\text { No. }\end{array}$ & Statement & $\begin{array}{l}\text { Strongly } \\
\text { Disagree }\end{array}$ & Disagree & Neutral & Agree & $\begin{array}{c}\text { Strongly } \\
\text { Agree }\end{array}$ \\
\hline 1. & $\begin{array}{l}\text { Using movies to learn } \\
\text { psychological concepts is } \\
\text { a useful way of learning }\end{array}$ & & & & & \\
\hline 2. & $\begin{array}{l}\text { Using movie clips is a } \\
\text { novel way to deliver/ } \\
\text { conduct group workshops }\end{array}$ & & & & & \\
\hline 3. & $\begin{array}{l}\text { Using movie clips } \\
\text { enhanced my } \\
\text { understanding of the } \\
\text { concepts }\end{array}$ & & & & & \\
\hline 4. & $\begin{array}{l}\text { Using movie clips helped } \\
\text { me to understand the } \\
\text { theoretical psychological } \\
\text { concepts in a more } \\
\text { realistic way }\end{array}$ & & & & & \\
\hline 5. & $\begin{array}{l}\text { Working on using movie } \\
\text { clips for workshop was } \\
\text { more time consuming } \\
\text { than other assignments }\end{array}$ & & & & & \\
\hline 6. & $\begin{array}{l}\text { Finding relevant clips } \\
\text { from the chosen movie } \\
\text { was a difficult task }\end{array}$ & & & & & \\
\hline 7. & $\begin{array}{l}\text { Film is a means of getting } \\
\text { young people enthusiastic } \\
\text { about their subject }\end{array}$ & & & & & \\
\hline 8. & $\begin{array}{l}\text { I am more confident when } \\
\text { talking about the films }\end{array}$ & & & & & \\
\hline
\end{tabular}




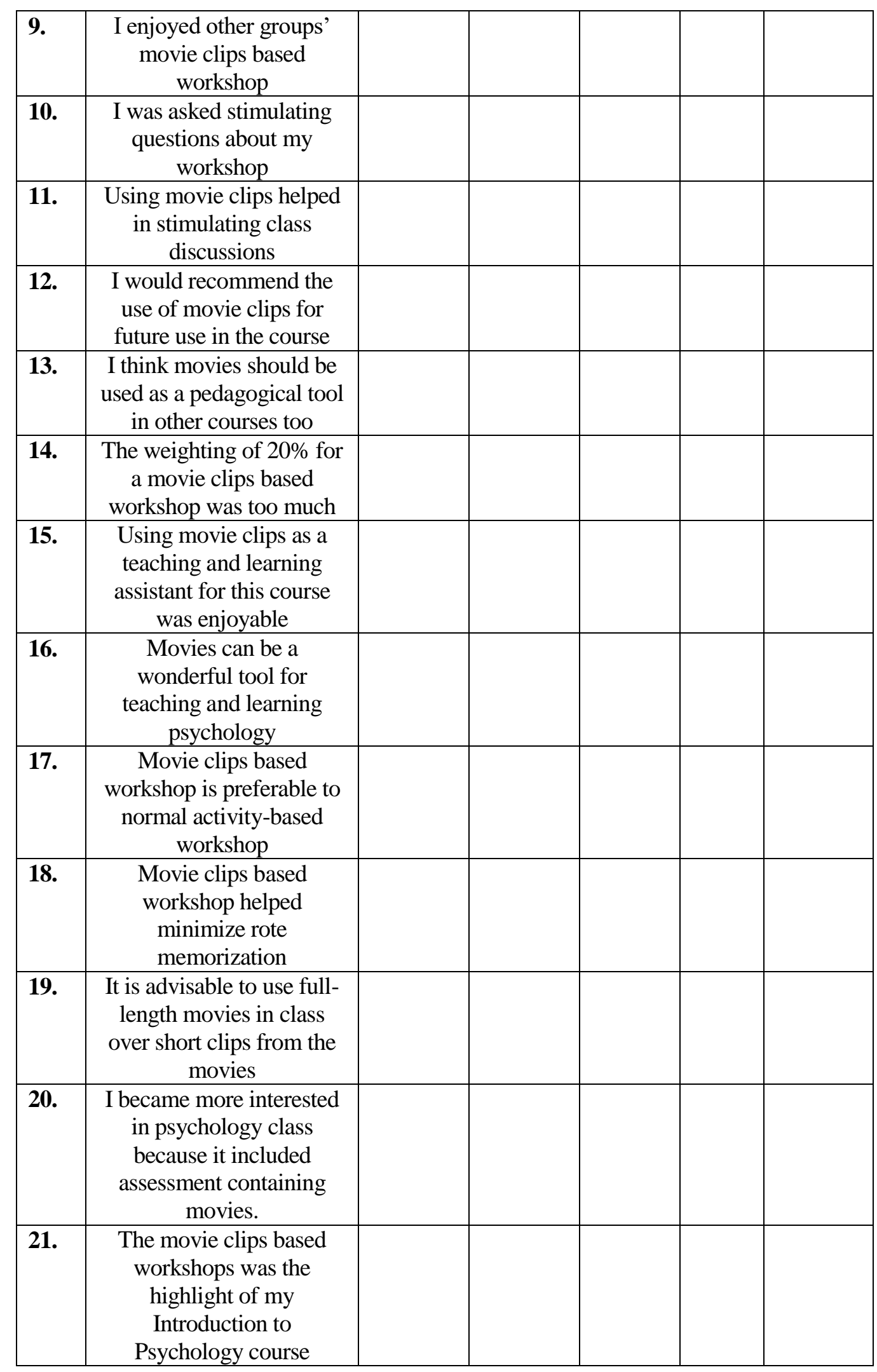

